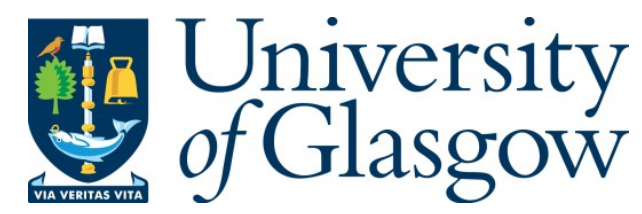

Schlesinger, Philip, and Doyle, Gillian (2014) From organizational crisis to multi-platform salvation? Creative destruction and the recomposition of news media. Journalism: Theory, Practice and Criticism . ISSN 1464-8849

Copyright @ 2014 Sage Publications

http://eprints.gla.ac.uk/93643/

Deposited on: 14 M ay 2014

Enlighten - Research publications by members of the University of Glasgow http://eprints.gla.ac.uk 


\title{
From organizational crisis to multi-platform salvation? Creative destruction and the recomposition of news media.
}

\author{
Philip Schlesinger and Gillian Doyle \\ University of Glasgow, UK
}

\begin{abstract}
Schumpeter's trope of 'creative destruction' aptly describes current transformations of news media whose business models are adjusting to the twin challenges of digitization and the Internet. While most production studies focus on the journalistic labour process, based on current empirical research into the UK press and access to key decision-makers, this article presents case studies of the strategies pursued by the Financial Times and The Telegraph in migrating from print to digital. It shows how new conceptions of the news business are being articulated by managements, how production is being reshaped and increasingly driven by data analytics, and poses questions about the impact of these changes on journalistic practices.
\end{abstract}

\section{Keywords}

Creative destruction, digital, Internet, management strategies, multi-platform, media, newspapers, production studies

\section{Corresponding author:}

Philip Schlesinger, CCPR, University of Glasgow, 13 The Square, Glasgow, G12 8QQ, UK.

Email: Philip.Schlesinger@glasgow.ac.uk

\section{Introduction}

In his famous work Capitalism, Socialism and Democracy, first published at the height of World War Two, Joseph Schumpeter (1950) formulated his well-known account of 'the process of creative destruction', which was founded on his view of how business cycles operate. There, he contended:

'The fundamental impulse that sets and keeps the capitalist engine in motion comes from the new consumers' goods, the new methods of production or transportation, the new markets, the new forms of industrial organization that capitalist enterprise creates.'

He continued:

'[T] he same process of industrial mutation...that incessantly revolutionizes the economic structure from within, incessantly destroying the old one, incessantly creating a new one. This process of Creative Destruction is the essential fact about capitalism. It is what capitalism consists in and what every capitalist concern has got to live in.' (Schumpeter, 1950: 83) 
We do not need to accept Schumpeter's particular critique of Marxism, nor indeed his view of the essence of capitalism, to acknowledge the potency of his metaphor and the pertinence of his insight to contemporary transformations of the media (and the cultural industries more generally) that result from the joint challenge to existing models and practices constituted by the internet and digitization. As Jean-Gustave Padioleau (2006) has noted, in Schumpeterian vein:

'Willy nilly, on the one hand, the media have to face up to their sorrow for a lost world (the prestige of the written word, for example) and, on the other hand, the coming of original and often enigmatic spaces of communication (the internet and mobiles). Creative destruction imposes a regime of trial and error and of making wagers. It does not allow you to rest on your laurels or established routines and images any more than it sanctions shifting your risk-taking onto the state. Journalism is condemned to reinvention.' (p. 110; translated from French)

Schumpeter's analysis of creative destruction focuses on technological change, and how innovations that emerge in response to this force existing businesses either to adapt or to die out (McCraw, 2007). Advancing technology brings opportunities but it also results in existing products and services losing ground. Thus, the value of large, dominant incumbent firms that fail to transform themselves eventually becomes eroded and, in some cases, completely destroyed. The relevance of this conception for recent developments affecting the newspaper industry is clear. While advances in digital technology and associated changes in news consumption and advertising patterns have opened up the opportunity for some new players such as the Huffington Post, many market incumbents have suffered significant upheaval. In the US, for example, numerous closures have taken place amongst conventional metropolitan and local titles and 'many laid off reporters and editors, imposed pay reductions, cut the size of the physical newspaper, or turned to Web-only publication' (Kirchhoff, 2010: 1).

In the UK national newspaper industry, which is the focus of this article, market incumbents have also been confronted by acute financial pressure on account of a decline in print circulation and advertising revenues. A central theme that we explore here, therefore, is how converging digital technology is forcing continuous adaptation in the organization of production activities within contemporary newsrooms as dominant press groups search out ways of making and supplying content that engage with and cater for the requirements of the digital era. We aim to present some initial findings regarding two major UK media enterprises - the FT Group (Financial Times) and the Telegraph Media Group (Telegraph) - and to show how they are responding to the crisis of a traditional print business model.

We have focused on how existing practice has been disrupted by the increasingly complex and ramified impact of digitization coupled with the challenge of content distribution through the Internet. Current evidence suggests that there is considerable cross-national variation in how audiences are responding to the multi-platform offer, which means that regulatory, economic and cultural 
conditions in given states play a large role in shaping enterprises' strategies. In the UK, for instance, while 'brands are being increasingly dis-intermediated by a growing range of pathways to their content', in the press and broadcasting they still remain strong focuses of attention, despite the shift to online delivery systems by younger - under-45 years - consumers (Newman and Levy (eds), 2013: 13-14).

Revolutionary times, as Padioleau rightly notes, bring new questions to the fore. But in journalism studies these draw on a well-established ethnographic tradition of analyzing the workings of major news media. Our present project is not in the classic 'production study' lineage, as its focus is on strategic decisionmaking and its consequences rather than everyday practices in newsrooms and reporters' interactions with sources. Building instead on the resource-based view of strategic management, one of our central concerns is how, in the interests of survival, individual newspaper groups are equipping themselves to address the demands of a changing environment through adjusting their resources and operational practices (Teece et al., 1997). Nevertheless, despite this difference of orientation, our current work is, in fact, highly complementary to research in the ethnographic tradition, not least because strategic decisionmaking has major implications for the organization of news work and the conditions under which journalistic production takes place.

Our approach - in addition to its strong focus on media economics - is also located in what Stig Hjarvard (2012) has called the 'sociological turn' in the study of journalism that first occurred in the 1970s. As the world of journalism has changed, quite reasonably, the limitations of positions staked out some forty years ago need to be reconsidered. The sociological turn, Hjarvard suggests, was mainly concerned with internal constraints and policies influencing news production'. This bends the stick too far as it would also be true to say that the research in question showed considerable awareness of the external contexts in which production took place - not least the political and economic constraints shaping the production of news. If the vantage point is to look outwards from inside an organization, then how external forces are translated into internal practices will inevitably be emphasized. But this does not mean that the outside world is being ignored.

Simon Cottle (2000) has suggested that the 'first wave' of production studies eventually became so orthodox in their impact on research that a break needed to be made with their assumptions and a 'second wave' of ethnographic research was required. In essence, his argument is that since the 1970s news culture has substantially diversified and therefore the objects of study have changed:

'Complexity and contradiction...obtain in [sic] respect to the introduction of new technologies, processes of digitalization and technological convergence that have recently reconfigured many newsrooms and changed journalist [sic] practices.' (Cottle, 2000: 33)

We agree that that the context for undertaking current research is indeed different from before and that the role of technological innovation has been key 
to changing the underlying conditions. We doubt, however, that the first wave of production studies acted as a blockage on research development. Rather, they have provided an essential platform for it. As the priorities and focus of research have changed, approaches have been updated and developed to suit a new agenda. But that is different from complete displacement. Ida Willig (2013), for example, has considered how, in contemporary investigations of the context for news production, established tools and theories of sociology might offer a useful developmental framework. In similar vein, Roel Puijk (2008) has reflected carefully on the continuities and differences of undertaking ethnography inside broadcasting organizations before and after the digital age, showing how technological change both affected production techniques and also the nature of fieldwork.

More broadly, in Mark Deuze's recent study of media work, it is argued that a key difference between earlier work focused on production routines and present-day conditions has been the 'current dogma of flexible production, increasing precariousness of employment arrangements, a globally emerging convergence culture, and an all-consuming shift of responsibility and accountability towards the individual' (Deuze, 2007: 86). Amongst other things, this line of development has involved situating media work in the context of the cultural economy, itself a line of inquiry that was elaborated subsequent to the 'first wave' of research.

Cottle is certainly right to emphasize the continuing importance of ethnographic research for revealing the internal workings of news organizations. Chris Paterson (2008: 3), whose work is reflexively presented as of the 'second wave', has also restated the view established in earlier research, namely that ethnographic work meant researchers did not need to rely for their knowledge of journalistic practice on content analysis and untested testimony by journalists. We would endorse this stance, although our present research has not taken the classic ethnographic path of observational immersion in the field.

We agree with Hjarvard (2012:93) that it is certainly pertinent to lay emphasis today on the dominance of 'market-driven' news and the role of media enterprises' management in mediating relations with owners, advertisers and audiences. Under conditions of 'convergence', the development of multi-media practices has been a key focus of much recent research, with due attention paid to how strategic change is reshaping cultures of production. The impact of technological innovation on the form of news itself, in particular its online enhancement, has been a major concern. And the complex impact of changes in technology on news workers has also been extensively discussed (Deuze, 2007: chapter 5 passim).

In contrast with, yet complementary to production studies which have addressed the labour process in newsrooms and the interactions between journalists and their sources, the focus of our present research is at the managerial level - the point at which attempts are being made to devise strategies for dealing with a rapidly changing environment, both in terms of how technology is impacting on the internal workings of what is rapidly ceasing to be 'the newspaper' and how the business itself might be reshaped to maximize revenues, and in particular, 
find new income streams. The capacity to evolve and reconfigure in changing environmental conditions is clearly a source of potential advantage for individual firms (Helfat and Peteraf, 2003). This level of decision-making has been relatively neglected in the field of production studies although some recent work has indeed included managerial perspectives in studies of changes in newsrooms and the associated implications for innovation and business strategy (Krumsvik, 2012; Picard 2011; Mico, Massip and Domingo, 2013; van Weezel, 2009). In line with the main focus of production studies, we have undertaken some observation in situ in order better to understand how production cultures are changing as a result of a transformation in business models. But that is not the prime objective. Instead, the purpose here is to extend critical understanding of the managerial and strategic considerations guiding organizational responses to technological change, which in turn, are transforming the context for news production.

We have conducted in-depth interviews with senior executives and managing editors. At a time of perceived 'crisis' in the economics of newspaper publishing with attendant concern about the future of news journalism (Siles and Boczkowski, 2012), this approach has enabled us to obtain some valuable insights into the forces pushing the reorganization and progressive mutation of newspaper publishing into a digital multi-platform industry. Our interviewees obviously believe that they are driving their enterprises towards viable solutions. Whether their strategies will prove to be correct is yet to be demonstrated. There are countervailing views. For instance, in recent research on UK news consumption, Thurman (2014) estimated that in 2011 some 96.7 percent of the time domestic readers spent reading newspapers was in consuming print editions. He further speculated that newspapers' decline might be slowed down by the nature and depth of audience engagement with print. But that view needs to be qualified as younger demographics favour online access and mobile devices more than their elders (Newman and Levy, 2013).

Turning now to the empirical detail of our study, we offer an analytical penportrait of the current strategies pursued by two major UK media organizations, the FT Group (FT) and Telegraph Media Group (TMG), in the full awareness that rapidly changing circumstances mean that the field will have to be revisited soon.

\section{FTG}

The FT Group is a division of Pearson plc, which has owned the Financial Times (FT) since 1957, and includes a number of other businesses involving financial analysis as well as the main newspaper title. Published in London, but now with a global reach, the FT has been a consistent online innovator in the newspaper world. It first launched its website FT.com in May 1995 and introduced subscriptions in 2002. In July 2006, the FT announced its intention to integrate the newspaper more closely with FT.com. This was coupled with a voluntary redundancy programme to cut 10 percent of its 500-strong editorial staff (Brook, 2006). A metered paywall was introduced in 2007. This was followed by the launch of an HTML5 mobile app in 2011. 
In 2011, the company had 2,765 employees with a turnover of some $£ 427 \mathrm{~m}$ (Pearson, 2012: 111; 168). From the standpoint of the present research, it is particularly important to identify how revenue streams have changed. In 2006, those coming from digital sales came to 14 per cent of income. By 2011, this had risen to 47 per cent, with digital customers rising from 90,000 in 2006 to 267,000 in 2011 (ibid: 24). Of major significance is the fact that by 2011, there were $4.3 \mathrm{~m}$ FT.com registered users - a major indication of the wider readership aware of the FT's online offer (ibid). Indeed, FT.com paying subscribers rose from 90,000 in 2006 to 316,000 in 2012 (Pearson, 2013: 23). The related fall in print circulation is noteworthy: this declined from 430,449 in 2006 to 273,047 in March 2013 (ABC, 2013). The overall impact of the growth of the digital offer, however, may be judged from how the combined circulation (print and digital) had risen to 602,000 in 2012, far exceeding the peak of print-only circulation (Pearson, 2013: 23).

\section{A networked business in the making}

In line with this evident shift from print to digital, on 21 January 2013, The Guardian published an email memo from Lionel Barber (2013a), editor of the FT, to his staff. This set out how he proposed 'to reshape the FT for the digital age' (p1) and sought to explain why the paper was seeking voluntary redundancies. The context was the disruptive effect on 'old titles' by 'new entrants such as Google, LinkedIn and Twitter. ...Our competitors are harnessing technology to revolutionize the news business through aggregation, personalization and social media. Mobile alone, for example, accounts for 25 per cent of all the FT's digital traffic' (p2). And then, in a telling phrase, Barber observed: 'We are moving from a news business to a networked business' (p2).

Ever since late 2006, along with the FT's CEO, John Ridding, Barber had been determined to lead a push to digital as a way of saving the paper (Interview, FT executive 1, 2012, p11). After the bankruptcy of Lehman Brothers and the ensuing crash in 2008, the existing strategy was significantly enhanced because the advertising market diminished dramatically as a source of revenue. The FT's leadership was extremely aware that technology giants such as Google, Apple and Amazon had reshaped the marketplace and fundamentally challenged print journalism's future. The company's digital wing, FT.com, looked to online retail businesses for its model recognizing that the subscription business is 'a direct internet retail business', which very few publishers knew and understood. Within the media field, the satellite broadcaster BSkyB was admired at the FT for its 'very, very smart use of technology and content packages to...constantly lever a bit more yield from their audience' (Interview, FT executive 2, 2012, pp2-3).

Barber wrote that the FT's decision to raise prices, charge for content and opt for subscription had been justified. He set out an eight-point plan that involved reducing 'the resources devoted to print' (p3). Summarizing the cultural change required, Barber stated: 'On unified news desks, we need to become content editors rather than page editors' resulting in 'a more dynamic and interactive form of journalism beyond the printed word. This is vital to drive deeper engagement with readers and build our subscription business' (p4). As one 
senior FT manager put it to us: 'People are wanting a kind of interactive, dynamic experience on line that's very different from the newspaper' (Interview, FT executive 3, 2012, p2). For instance, the creation of reader communities recognized at the FT to be a special strength of The Guardian newspaper in London - is one goal. The highly respected FT economics columnist, Martin Wolf, is seen as exemplifying this kind of contact. The FT blog Alphaville is also seen as a way of building online communities (Interview, FT executive 1, 2012, p4). The paper also holds monthly teas with readers who talk to staff and comment on particular articles and the effectiveness of the digital presentation. As a key figure at FT.com commented:

'[It] helps so much to have that feedback loop and it's absolutely essential to make a success of the digital age, really critical. And a lot of the editorial guys haven't been engaged in that so it's opening their eyes a little bit, making them feel the feedback and the interactions.' (Interview, FT executive 1, 2012, p5)

The aim is seek reader engagement and multiple visits from subscribers, to move the business model towards subscription and away from dependence on advertising, to turn the FT into a global newspaper and to exploit the trusted financial news brand that people are willing to pay for. It is still possible to read 8 articles a month for free on the FT's sites. Return readers are encouraged to take out a subscription.

In line with Barber's summary account, therefore, our interviews reveal the detailed impact inside a newspaper of the process of transformation. Indeed, the senior staff see this as a transition from the newspaper to a combination of print with a website, mobile platform and apps - Barber's networked business.

The FT's new course has entailed a number of key changes. It has resulted in simplified editionizing, meaning a shift from separate UK, European, US and Asian editions to a common global edition. FT executives wondered whether UK subscribers - who still constitute about 50 percent of the readership - would 'buy' this. The FT has also aimed largely to eliminate time-based editions by way of continuous website updating. The FT's current iPad app has both 'live' and 'morning paper' options, reducing the choice.

The FT's management has also sought to change the newspaper's revenue base: currently some 50 percent of the FT's revenues come from advertising, a decline of around 20 percent in the past decade. Advertising is seen as an uncertain source, being volatile because of the vagaries of the business cycle and also as increasingly subject to competition because of the increasing movement of advertising revenues from print to digital and the strong market position in the digital space of players such Google, Apple and Amazon. The ambition is drive up subscription or 'content revenues' so that in the next few years these become the main basis of the enterprise's revenues (Interview, FT executive 4, 2012).

This has meant that there is a powerful incentive to move increasingly from print to digital distribution. The rationale is that to increase digital subscribers is cheap, with low marginal costs, and furthermore that digital distribution vastly 
increases the FT's potential reach. In 2011, for instance, FT Chinese exceeded more than 1.7 million registered users.

\section{Reshaping news production}

These strategies clearly play into how news production is being reorganized - a question much discussed in the academic literature. At the FT, there has been a decisive shift from print to digital jobs, with the creation of a live news desk and the creation of new roles. A lucid and detailed description of this emergent 'web first' culture came from a senior figure in FT.com:

'We have 100 more journalists than we did previously. If you break down what they are doing, the bulk of them are still involved in content origination/reporting or columnist activities but that is now being supplemented with creation of content in different styles. So we have video specialists. We have interactive graphics specialists. We have blog editors. All these are categories of expertise which we didn't have ten years ago, and there is now a large cadre of people who focus on these things and that continues to extend. So we have a mobile editor. We have a social media editor. And we expect those functions will continue to develop over time. And then you have got the whole sub-editing or editorial production function, [which] I guess is probably a more generic way to put it. I mean, that is changing to the extent that there are now editorial production resources working across both print and online and mobile and their skill set is necessarily changing, the way they work is changing, the time of day they work is changing as well, because the newspaper is a very lumpy process where all the content gets spat out at, kind of, 4 or 5 o'clock in the afternoon from the journalists and then turned into a paper very rapidly for production and distribution during the evening. And online is a 24-hour process which is much, kind of, smoother in many ways from a publishing point of view.' (Interview, FT executive 2, 2012, pp4-5)

In terms of the organization of work, this has meant moving away from a oneday print cycle to having journalists write more frequently to keep the site dynamic' - thus, how stories are written changes (Interview, FT executive 3, 2012, p12, 16). It is recognized that this is a fundamental shift in production culture. If news production can be seen as a time-machine of daily creation, traditionally bounded by a predictable 24-hour cycle (Schlesinger 1977), then that model - in true Schumpeterian mode - has begun to undergo a fundamental process of destruction, neatly summed up as follows: 'The lovely part about our daily newspaper is it's a daily cycle. You get something done at the end of every day and you feel like, "Yes, tick the box." Problem with the digital age is it's never done. You get it out, you still have to change it, you know, and the story never stops - and that's a struggle' (Interview, FT executive 1, 2012, p4).

This kind of change is very challenging to established conceptions of how a newspaper works. Our informants were clear that 'the FT is not a breaking-news site. We are not the BBC.' However, at the same time, for certain stories that are seen as typifying the FT's expertise - such as the appointment of the new Governor of the Bank of England, Mark Carney, on 26 November 2012 - being 
the first to break the news is especially important (Interview, FT executive 1, 2012, p5).

The changed cycle has meant moving away from long-established shift patterns based on a printing cycle, with some staff coming in earlier and fewer needed later. Currently, the news staff are divided broadly 50:50 between print and digital but the shift (as Barber noted in his email) will increasingly be towards digital. Related to this are 'more flexible' work patterns. This has gone hand in hand with several rounds of redundancies which, we were told, was not about 'reducing head count' but rather about 'losing staff who have skills we no longer require and bringing in staff that have got the skills that we will need in the future' (Interview, FT executive 2, 2012, p6).

However destruction of the old to make way for the new is not without its challenges. Previous newsroom studies have highlighted some of the frictions involved in embedding a fully converged approach to content production (Erdal, 2011; van Weezel, 2009). One instance we have found in our research of how adherence to the traditional routines and practices of print production may frustrate change is the misalignment which, despite copious volumes of return path data, still occurs between spikes in usage of online versions of newspapers and the daily publication cycle. One senior manager conceded that, whereas the number of stories published every hour at FT.com throughout a 24-hour period typically increases very markedly in the early evening when the print edition of the newspaper is approaching its production deadline, the known peak periods in usage of FT.com occur elsewhere in the day. This very concern was addressed in an open memo from the FT's editor, Lionel Barber, to the newspaper's staff in October 2013. This called for journalists to 'publish stories to meet peak viewing times on the web rather than old print deadlines' (Barber, 2013b).

Even for companies such as the FT Group, overcoming the conventional rhythms of news production so as to align the cycle of production with patterns of online usage can be a struggle. And the $F T$ is by no means alone in this. Other leading UK press groups, all of whom lag far behind the FT in promoting a 'digital first' approach to production, acknowledge the difficulties that pertain in ensuring that online content is refreshed at such times and with a frequency that encourages high levels of engagement amongst digital users. Looking beyond the UK, an analysis carried out internally at the Wall Street Journal in Spring 2013 showed that even though the peaks of online consumption occur elsewhere during the day, journalists at WSJ.com are still posting copy in accordance with traditional print deadlines (Romenesko, 2013).

Along with changes in the news cycle, not surprisingly the pattern of editorial conferences has also changed. There are two conferences per day, the first being the traditional agenda-setting one in the morning whereas the second, in the afternoon, reviews web analytics to see how stories have been doing. While currently, as one senior manager put it, 'We are very resistant to editing by numbers', the web analytics - it was conceded - might drive narrower story selection much more in future. 
In fact, web analytics have become central to developing the emergent business model. As one of the FT's financial executives put it: 'I can see through our analytics exactly what...people are doing on the site and am actually understanding their behaviour and their needs...and judge from their behaviour as to which parts we can improve, and that leads to product innovation' (Interview, FT executive 4, 2012, p6). Knowledge about readers has become increasingly important and this has led the $F T$ to try to control the relevant data as much as possible and has set off a process of dis-intermediation. For instance, the paper launched its own HTML5 app in preference to dealing with its customer base through iTunes. This required considerable long-term investment, building up a specialist team of software engineers within FT.com. The FT has also tried to recapture corporate users that seek its content through paid aggregator sites. Exceptionally, it accepted that in order to remain indexed by Google it needed to allow users free access to their service: 'We negotiated that. Now it's down to fifth click, pay now. ... We monitor that very closely. If we see people abusing it, Google has given us the right to stop it, particularly at corporate level' (Interview, FT executive 1, 2012, pp7-8).

Furthermore, the sophistication of web analytics has offered much more precise feedback to advertisers about campaigns. It has also allowed the FT to tailor its content to users based on their browsing behaviour allowing them to 'frame and shape that product so it answers the need of the user at that time' (Interview, FT executive 4, 2012, p9). The use of web analytics has started to pose new problems for the exercise of journalistic judgment and conceptions of professionalism. It has broken down beliefs about the need to sequester news values first, from audience feedback and second, from technology and commercially-driven concerns to enhance the attractiveness of the product. This is in line with what Deuze (2007) noted a several years ago:

'As media companies are beginning to integrate the emerging creativity of producing consumers this in turn changes the ways of doing things for media professionals, who now have to find ways to incorporate their audiences as colleagues in the creative process.' ( $p$ 95)

Users are not quite 'colleagues', to be sure, but they are evidently increasingly impactful. Thus, in respect of making items more prominent because of feedback received, the $F T$ editorial staff were careful to stress that

'We are not going to edit by numbers. But we can know that first thing in the morning while you are commuting into work, you're more interested in reading about your sector in particular, therefore that will be your first view. ...You don't want to go so far down the line of personalization that you don't expose the serendipity. ...We do recommended reads on the web app and that's based on your browsing behaviour' (Interview, FT executive 1, 2012, p6).

Our informants were keen to stress that journalistic judgments still held prime position: 'We are not anywhere near like [title $x$ ] where we have people coming down and saying "You have to change your headline to this or that." We don't do 
that. But we have one of our specialists sitting with the newsroom and just helping them, so they will come to my guys for advice on "I am going to do a special on Africa and this is the slant. ...What's the best way to discover that? What kinds of tags should we use?" We get advice but we don't determine. That's very much editorial's decision' (Interview, FT executive 4, 2012, p14).

In a droll play on words, this role was described as making headway with the 'moreons': 'more on this story, more about that topic. ... So it's generally not about the core story. It's about this stuff around it that makes it come to life' using interactivity, pictures, slide shows, and videos (Interview, FT executive 4, 2012, p15).

Significant tensions have begun to emerge between enhancing the discoverability of the FT's content in order to build the relationship with the customer and subtly shifting editors' news judgments about what matters - all in the cause of growing the revenue stream deriving from increased purchases of digital content.

\section{TMG}

Telegraph Media Group (TMG) is the proprietor of The Daily Telegraph and The Sunday Telegraph. It is a subsidiary of Press Holdings, which is owned by the billionaire brothers, David and Frederick Barclay, who acquired the group in 2004.

TMG has over 1,000 employees with a turnover in 2011 of more than $£ 331 \mathrm{~m}$ (Telegraph Media Group, 2012: 12; 1). Although plans to charge for online access were first formulated in 2010, The Telegraph began metering content for UK readers in March 2013. However, as a precursor to this, charges were introduced for The Telegraph iPad app in May 2011. In March 2013, TMG announced the complete merger of its daily and Sunday titles. This was accompanied by a cut of 80 print jobs with a promise to create 50 digital ones.

The Guardian published TMG CEO Murdoch MacLennan's message to the staff concerning these changes on 12 March 2013 (www.guardian.co.uk/media/2013/mar/12/telegraph-group-job-cuts-letter) MacLennan noted the decline in print advertising and a contraction in newspaper sales. The business had to diversify its revenue streams, he wrote, so 'we must move now to complete our transition to a digital business'. The second shift he required was to merge the editorial operation 'into one unified operation, serving digital and print products on a $24 / 7$ basis. This operation will require the very best digital talent available. ...This is only part of the change, because we need to bring a new, sharp focus to our editorial operation to ensure that digital takes the leading role...an all encompassing operation, to transform newsroom culture into a dynamic process with our digital products at its core, and to recruit the best talent - across web, tablet and smartphone.' The ambition, MacLennan concluded, was to become 'the world's foremost English-language multimedia news and content provider' (p2). 
On 27 February 2013, the week before The Telegraph began to meter reader access to its content, MacLennan gave a public lecture at the Adam Smith Business School of the University of Glasgow. Ranging widely, and further elaborating on the strategy set out his letter to staff, he said that for newspapers the extraordinary changes in digital technology constituted an industrial revolution. The world had changed, he observed, and media companies were 'at the apex of transformation'. That meant the business model had to change from a high to a low cost one. In this transformed world, the competition for The Telegraph was not The Times or the Daily Mail. Rather it was the broadcasters the BBC - and news websites. Indeed, in response to questions after his lecture, MacLennan said that aggregators were 'engaged in stealing' customers. The new form of content provision was both an opportunity and a danger for the press. Income at The Telegraph now came 50 percent from each of advertising and circulation.

He went on to note that as consumer behaviour and advertising were more and more shifting online, this meant that data analytics were at the forefront of informing news judgments. In this context, it had become necessary to reinvent The Telegraph to attract a bigger and younger readership. The daily sale was 571,000 , whereas digital sales were now running at 320,000. Of the 61 million unique users yearly only 23 million were in the UK. The Telegraph had become a global proposition. It was the UK's seventh most popular website, he said, and received some 20,000 comments a day. Visits to the website had increased tenfold since 2006, when the digital and print operations were first integrated. The average age of readers was now 46. Apps were increasingly important: The Telegraph had become a 'wrapped-in brand' with doubled growth in digital access and a threefold increase in mobile use. What the paper had to do was to 'follow consumer behaviour and get ahead of the customers'. The key objective was to survive in global competition. 'Investment in quality' was what was needed. People were of key importance, especially the possession of 'crossplatform skills'. MacLennan concluded his lecture by saying that technological innovation was key. So, for instance, live video streaming had been part of the offer since 2012. There was a 'need to know the viewers and readers intimately' and to that end they had been in partnership with Vodafone and various banks as data management was key.

Murdoch MacLennan thus laid out the broad trajectory intended for The Telegraph. Our interviews went into further depth with key executives inside the company.

\section{Changing platforms}

The newspaper has undertaken a far-reaching process of change that is still under way. The strategy has remained rooted in print - increasingly combined with digital services - while, at the same time, its management realizes that over time the output will move increasingly, if not exclusively, to digital platforms and that this will ultimately represent the inherent value of a firm like The Telegraph' (Interview, TMG executive 1, 2012, p2). Inside the group, therefore, the gradual development of a new business model has been likened to a journey. 
Reflecting on the path taken over the past twenty years, a senior digital editor remarked:

'In 1994 we were the first national newspaper to launch a website and it was...just about...playing around with the technology. And at that time, in 1994, very few people would have had the foresight to realize how transformative it would be to the news industry. Had they had that foresight, I don't think that they would have given the content out for free. ... They may have done so for a period of two or three years but I think they would more rapidly have introduced a payment system too. ...The narrative that was prevalent, sort of four, five years ago, which was that people won't pay for content, you have just got to put it all out there and it was about driving advertising and the larger numbers that you need to drive advertising, I think is outdated.' (Interview, TMG executive 1, 2012, pp9-10)

In many respects, and this is hardly surprising, the diagnosis of the problem echoes that reached at the $F T$ but has been arrived at more slowly. There was a need, we were told, in phrases that matched those of Murdoch MacLennan, to escape from the high cost, high revenue model of print to embrace digital production and distribution. The shift was presented as efficient because it gave access to 'relatively large numbers of people at relatively low cost' both for advertising and for editorial (Interview, TMG executive 1, 2012, 4). The New York Times is seen as a newspaper making a successful transition from an exclusive print base by charging for its digital content. Its 166,000 digital subscribers and claimed \$US100m revenues were noted approvingly in 2012 (Interview, TMG executive 1, 2012, p10). The sense of how this shift may challenge the very conception of the news business's place in the world may be illustrated by this quote:

'We have for 158 years been an organization that has only reached people in Britain. And now we have more than 50 million users, two-thirds of which are outside the UK and one-third of our audience is in the US...70 or 80 million users.' (Interview, TMG executive 1, 2012, p4)

Aside from the continuing decline in print circulation, Telegraph management also noted the 'very big challenge' represented by 'the compression in advertising yields' (Interview, TMG executive 1, 2012, p11). So how has The Telegraph shifted its ground? It is important to note that, while print editions remain very important in terms of revenue generation, now TMG's leading figures no longer see it as just a newspaper but rather see the newspaper as an essential part of a multi-platform business. As a senior technology executive put it:

'One of the key things that we set out to do from a business perspective but also from a technology perspective is to make sure that you don't throw the baby out with the bathwater. So rather than just do big, full steam ahead at only digital, it's making sure that there is a package of stuff that, in terms of experience, makes 
sense across platforms - and that includes print.' (Interview, TMG executive 2, 2012, p1)

Consequently, TMG has sought to 'add value' to the print subscription by giving loyal subscribers access to the iPad edition and mobile apps, the idea being that this is experienced as a 'premium subscription'. It makes good sense to nurture the subscriber base, which - at 300,000 - is higher than that for any other UK national generalist newspaper. Holding on to this base, in the short to medium term, is seen as key to managing 'the business through the transition where you are obviously going to end up needing a lot more volume in digital' (Interview, TMG executive 2, 2012, p2).

It is widely recognized at The Telegraph that mobile devices hold the key to future consumption of content; indeed these are seen as dominating the next 510 years. The launch of the iPhone in 2007 was seen as a turning point, a shift from 'the web era to the mobile era' (Interview, TMG executive 1, 2012, p3). The change in sensibility about how to connect with what is variously described as the audience and customer (and hardly ever at all as the reader) means that there is a continuous search for new ways of developing The Telegraph as a 'brand' and of finding ways of building loyalty on the part of the customer - a process labelled 'engagement'.

One way of changing the offer has been to launch new sites in the fields of fashion and travel, where it is known that advertising will do well, and these have already proven to be profitable. In part, the shift of distribution to the iPad and other tablets has been seen as an advantage (Interview, TMG executive 1, 2012, p5). There is a well-tuned sensitivity to how making use of interactivity can 'spur loyalty' on the part of the reader:

'Fast track to where we are in two or three years, what we need to be knowing is that a particular reader spends 70 percent of their time on the crossword. ...When we have an innovation, we should go and touch that person right away.' (Interview, TMG executive 1, 2012, p6)

Such intimate knowledge has become feasible through tagging page traffic and making use of increasingly sophisticated web analytics. The crossword example is not fortuitous. The Telegraph has discovered the importance of time spent on games on mobile devices: 40 percent of iPad app use is doing crosswords. There is also a double advantage in using metering to control access to the content. Presently, a registered user can access up to 20 free articles a month. According to one senior manager:

'The metre is for two reasons. One is you want to maintain reach. And the second thing is that you want to have a prospect pool of people that are essentially sampling what you have to offer. So, if we went completely behind a wall, then new potential customers wouldn't necessarily try us and therefore we are going to be limiting in the long run our total subscriber number.' (Interview, TMG executive 2, 2013, pp3-4) 


\section{Changing news work}

The way The Telegraph's business model has changed has had major consequences for how the journalistic production process is organized and also for how journalistic practice is conceived. All journalists under contract to TMG work for The Telegraph's multi-platform operation and produce copy for the web and other forms of digital distribution as well as the papers. The news operation, we were told, is about 85 percent 'integrated' as between print and digital production. As a precaution, the company has retained print specialist capacity in the evening team that produces the following morning's newspaper, to avoid any distraction as to how the web pages look (Interview, TMG executive 1, 2102, p12).

Nevertheless, during the 2012 Olympics, the newsroom was expected to think both about how the story was playing out on the web and, at the same time, consider what would be done in the next day's newspaper. This is just one instance of a new way of thinking about the multi-platform offer. Our informants told us that journalistic work was increasingly seen as 'holistic in terms of the narrative, or to be taking care of everything from the headline, the words, the selection of pictures, the selection of the video' (Interview 2, TMG executive 1 2013, pp4-5). Increasingly - in a term now bandied around many media businesses - the editorial team has become much more 'curatorial' in function.

The interaction between digital and traditional forms of journalism also came into play during preparations of The Telegraph's celebrated revelation of the MPs' expenses scandal (Winnett and Rayner 2009). As we were told:

'Where we have 1.5 million documents, having the skills to dig into that database and select this information is where you need old school journalism skills. You need to know what you're looking for because it's a vast array of information but then you need the new skills, which is how to pull out the information in a relatively short period of time.' (Interview, TMG executive 1, 2012, p16).

The newspaper had played its digital first card in order 'to capture the attention of the general public through the TV broadcasters' (Interview 2, TMG executive $1,2013, \mathrm{p} 8)$. The question of whether the story was print or digital was not the issue - rather it was a matter of achieving maximum impact.

However, this is evidently the last gasp of the old order. What we do not yet know is how long this transitional phase will last. There have been significant changes in staffing over time, with hires in new areas and fires in the old. While it has proven difficult to obtain precise figures due to commercial sensitivity, it is estimated in-house that some 25 percent of the staff in a newsroom of some 500 are now exclusively focused on digital production, compared to some 10 percent in 2007 (Interview, TMG executive 1, 2012, p18). Fourteen staff are now assigned to video production; five work on interactive graphics - skills that, for instance, were simply unrecognized as needed in the very recent past. It is acknowledged by company strategists that as The Telegraph moves increasingly 
towards being a primarily digital operation, it will need fewer staff (Interview, TMG executive 1, $2012 \mathrm{p} 19$ ).

Murdoch MacLennan's observation that it is broadcasters and aggregators that are now the key competition for The Telegraph rather than other newspapers is highly pertinent to the current evolution of the business. Tremendous attention is paid in the newsroom to what is trending on sites such as Twitter and Facebook and also to the lifespan of stories and the page views they attract. The editor of the print edition and the editor of the website - Telegraph.co.uk-meet each day at a news conference to discuss their respective stories. The discussion begins with the online proposals and then it moves on to print.

'The SEO [search engine optimization] guys talk about what's trending on Google. We then talk about what's trending on Twitter. We then talk about what our readers are sharing of our stuff on Twitter and Facebook. So what among the top five they are sharing on each of these. And we talk about what are the most commented on - so, which articles are getting the most comments.' (Interview, TMG executive 3, 2013, p1)

Apart from affecting how the website is adjusted to address this kind of feedback, the clustering of readers around particular stories is also affecting how The Telegraph's management is increasingly thinking about the brand itself.

'We have been putting more analytics in the hands of editors and journalists over the last few years and one of the tool sets they have got basically works in real time, so you can see how people are engaging with content, we can see what is popular right now, you can see all of that. And as they get more comfortable with driving decision-making on an hourly basis based on analytics, you can begin to add more to the mix.' (Interview, TMG executive 2,2013, p8)

On the one hand, the company claims to have extended the range of forms through which content is supplied by a daily posting of some 50 videos, 25 blogs and 10 picture galleries. However, enhancement through range is not seen as a complete solution to the problem of audience building. Company strategists think the key to future success is to ensure that a small cluster of daily stories between three and five - will carry and define the brand. To the extent that this will be implemented in the near future, it will steadily take The Telegraph away from the comprehensive conception of broadsheet news prevalent only a few years ago to one of highlighting a few main stories in ways that are much more characteristic of broadcast news. This line of thinking was well expressed in the following comment:

'I think there is merit, actually, for a lot of organizations, in just saying, "Well, how could we get a bigger impact with fewer stories?"... I mean, maybe as few as 30 stories a day, and do them really, really well. And you may publish many more than 30 stories a day but you might be promoting and pushing aggressively a relatively small number of stories.' (Interview, TMG executive 1, 2013, p7) 
We have noted that at the FT there were unresolved tensions. These concerned, on the one hand, the trade-off between news judgment and journalistic autonomy being conceived as the professional bedrock and, on the other, decisions about content being driven by 'the numbers' embodied in web analytics. Not surprisingly, similar contradictory strains were also evident at The Telegraph. Nonetheless, managers still maintained that the 'editors are guardians of the brand...and good editors will always be rigorous about that' (Interview, TMG executive 1, 2012, p9). It was also remarked that while 'You can see where all your traffic is coming from...you can't be led too much by it. You have still got to go with some of your instincts. You can't completely edit to the analytics' (Interview, TMG executive 3, 2013, p4).

The Telegraph is still addressing the matter of how best to achieve a balance between the drive to update stories and the need to offer added value to reinforce reader 'engagement', seen as essential to growing the subscriber base. An example given to illustrate how the problem was being managed concerned GDP figures issued by the UK government:

'We will put out a holding story, a headline and [be] very brief. We will give our economics editor a couple of hours to really get the story right, as opposed to breathlessly updating the story. ... At the end of the day, it's about good news judgments and from that point of view, the dynamic hasn't shifted.' (Interview 2, TMG executive 1, 2013, p6)

The big shift in priorities, however, is reflected in the view that 'digital first' is largely meaningless because now online has general priority:

'The only copy that doesn't really go up online first are some of the sports columnists... anything under embargo, obviously. ... We hold back some investigations for the paper. There is some stuff that we will put up at 7 o'clock the next morning on the basis that actually it will do better in search or with Google traffic. ... On the whole, people are writing for online first.'

The Telegraph is informed by its increasingly sophisticated knowledge of when stories are being read, and by whom. Consequently, it publishes stories that will hold up when they are likely to achieve the highest readerships; and when necessary, it also obeys the imperative of breaking news.

\section{Conclusion}

In a recent analysis of US regional daily newsrooms, David Ryfe (2012) has shown how difficult it can be to solve the present crisis of print journalism. In one case study, he demonstrates how a considered attempt by a well-established city newspaper to 'divorce content production from platform' (Ryfe 2012:136) ran into cultural resistance by editorial staff, not least because of the challenge posed by making a transition from print to digital for established journalistic self-conceptions and work practices. Driven by management, although without a clear strategy, the attempt to repurpose the enterprise was still in question when he concluded his fieldwork. Although he does not invoke Schumpeter, the 
internal organizational meltdown that Ryfe describes is plainly one potential outcome of the process of creative destruction.

We cannot be sure, obviously, whether the strategies described in our two case studies for effecting the transition to digital first and foremost will actually work. Our focus - from a standpoint of critical distance - has been on how management sees the problem rather than on how this has been received on the shop floor. That question needs further research. Clearly, however, as the initiative lies with management, this in itself tells us a great deal about relative power relations inside news organizations as they pursue technological innovation (Domingo 2008: 27). If, over time, the workforce becomes reshaped by reskilling, hiring and firing, at least one key managerial precondition for securing the drive to digital will have been met. For the more comprehensive analysis we intend to provide, research into both adaptation and resistance to managerial strategies is needed.

The two enterprises we have studied differ greatly. The FT addresses economic and political elites. Because of its specialized content, it occupies a niche position in the UK market place and has very few serious competitors globally, the Wall Street Journal being the most notable. The Telegraph is a conservative quality broadsheet that has still managed to keep a significant UK print readership, while finding a new, global audience for its digital content. In both cases, almost at the same moment, each newspaper's management decided to press ahead with a new stage of its digital strategy. In both cases, the decline of established sources of revenue - advertising, print sales - prompted the drive to find new ones. This means that building relationships with 'customers' by enhancing content has become key. However, because of its ability to invest in the production of an HTML5 app, the FT managed to secure much greater control over the data deriving from its digital return path than has The Telegraph.

Both companies are engaged in reshaping their editorial operations. As part of its transitional strategy, The Telegraph has quite consciously held back on full integration of its print and digital operations. The FT is clearly going to move ahead more fully if it can. In both cases, not surprisingly, the potential (and actual) reach offered by the digital distribution of content is well recognized.

The shift to digital has had consequences for the organization of the production time-cycle and has minimized the need to have numerous print editions. The FT's iPad app offers a choice between the 'live edition' and the 'morning edition' (the latter being identical to the print version). For both papers, the use of data analytics has changed how stories are assessed for significance and duration and this has posed a new challenge to established notions of editorial judgment. At the same time, the traditional routines and values associated with print production continue to exert a strong sway, as is evident from a mismatch at F T.com and other titles between recognized peak periods in online news readership and hourly patterns in online publication of stories by journalists. The forces of creative destruction have yet to deliver the newspaper industry from crisis to salvation. Moreover, as the present transformation places ever-greater emphasis on data-driven models 
within newsrooms, inevitably new questions will be posed concerning the nature of journalistic practice and its legitimations.

\section{Acknowledgements}

We wish to thank our informants for giving so generously of their time and their willingness to explore the questions that interest us. We also wish to thank this journal's reviewers for their constructive and insightful comments.

\section{Funding}

We gratefully acknowledge the support of the UK Economic and Social Research Council for 'Multi-platform media and the digital challenge: strategy, distribution and policy' (ES/J011606/1). The project runs from July 2012-June 2015. As well as examining the profound transformations occurring in the press, the wider project will also address related developments in UK television and magazines.

\section{References}

ABC (2013) ABCs: National daily newspaper circulation March 2013. The Guardian, 12 April. Available at: http://www.guardian.co.uk/media/table/2013/apr/12/abcs-national-newspapers (accessed 12 A pril).

Barber, L (2013a) Lionel Barber's email to FT staff outlining digital-first strategy. Available at: http://www.guardian.co.uk/media/2013/jan/21/lionel-barber-emailfinancial-times/print 5 pages

Barber, L (2013b), Lionel Barber memo to staff on reshaping the newspaper for the digital age, Financial Times, 9 October. Accessed at: http://aboutus.ft.com/2013/10/09/lionel-barber-memo-to-staff-onreshaping-the-newspaper-for-the-digital-age/\#axzz2nLqtkmY3

Brook, S (2006) FT cuts 50 jobs in newsroom merger, Guardian, 11 July. Retrieved at: http://www.guardian.co.uk/media/2006/jul/11/financialtimes.digitalmedia

Cottle S (2000) New(s) times: towards a 'second wave' of news ethnography. Communications 25(1): 19-41.

Deuze, M (2007) Media Work. Cambridge: Polity.

Domingo D (2008) Inventing online journalism: a constructivist approach to the development of online news. In Paterson C and Domingo D (2008) Making Online News: The Ethnography of New Media Production. New York: Peter Lang, pp.1528.

Erdal I (2011) Coming to terms with convergence journalism: cross-media as a theoretical and analytical concept. Convergence 17 (2): 213-223.

Helfat, C and Peteraf, M (2003), The dynamic resource-based view: capability lifecycles, Strategic Management Journal 24 (10): 997-1010. 
Hjarvard S (2012) The study of news production. In Jensen K B (ed.) A Handbook Of Media and Communication Research (2 ${ }^{\text {nd }}$ edn). Abingdon: Routledge, pp. 87105.

Kirchhoff, S M (2010) The US Newspaper Industry in Transition. Congressional Research Service. A vailable at: www.fas.org/sgp/crs/misc/R 407000.pdf

Krumsvik, A (2012). Why old media will be funding journalism in the future. Journalism Studies 13 (5-6): 729-741.

McCraw, T (2007), Prophet of Destruction: Joseph Schumpter and Creative Destruction, MA: Harvard University Press.

Mico, J, Masip P and Domingo D (2013) To wish impossible things: convergence as a process of diffusion of innovations in an actor-network. International Communication Gazette 75 (1): 118-37.

Newman, N and Levy D A L (eds) (2013) Reuters Institute Digital News Report 2013: Tracking the Future of News. Oxford: Reuters Institute for the Study of Journalism.

Padioleau J-G (2006) Les médias face à la destruction créatrice. Débat 139: 109121.

Paterson C (2008) Why ethnography? In Paterson, C and Domingo D (2008) Making Online News: The Ethnography of New Media Production. New York: Peter Lang, pp.1-11.

Pearson PLC (2012) Annual Report \& Accounts 2011, London: Pearson PLC.

Pearson PLC (2013) Annual Report \& Accounts 2012, London: Pearson PLC.

Picard R (2011) Mapping Digital Media: Digitization and Media Business Models. London: Open Society Foundation.

Puijk R (2008) Ethnographic media production research in a digital environment. In Paterson, Chris and Domingo, David (2008) Making Online News: The Ethnography of New Media Production. New York: Peter Lang, pp. 29-41.

Romenesko J (2013), WSJ staffers told to 'stay the course - and accelerate', Jimromenesko.com/2013/03/10/wsj-staffers-told-to-stay-the-course-andaccelerate/

Ryfe D M (2012) Can Journalism Survive? An Inside Look at American Newsrooms. Cambridge: Polity.

Schlesinger $P$ (1977) Newsmen and their time-machine. British Journal of Sociology 28(3): 336-350. 
Schumpeter J A (1950, 3 $3^{\text {rd }}$ edn) Capitalism, Socialism and Democracy. London: Unwin University Books.

Siles I and Boczkowski P (2012), Making sense of the newspaper crisis: a critical assessment of existing research and an agenda for future work. New Media \& Society 14 (8): 1375-1394.

Teece, D, Pisano, G and Shuen, A (1997), Dynamic capabilities and strategic management, Strategic Management Journal 18(7): 509-533.

Telegraph Media Group (2012), Report and Account for the Financial Year ending January 2012, London: Companies House.

Thurman $N$ (2014). Newspaper consumption in the digital age: Measuring multichannel audience attention and brand popularity. Digital Journalism 2(2), doi: 10.1080/21670811.2013.818365 http://dx.doi.org/10.1080/21670811.2013.818365

Van W eezel A (2009), Organisational changes in newspaper firms and their relation to performance. International J ournal on Media Management 11: 144-152.

Willig I (2013) Newsroom ethnography in a field perspective. Journalism: Theory, Practice \& Criticism, 14 (3): 372 - 387.

Winnett R. and Rayner G (2009) No Expenses Spared. London: Transworld Press.

\section{Author biographies}

Philip Schlesinger is Professor in Cultural Policy at the University of Glasgow and Deputy Director of CREATe, the RCUK Centre for Copyright and New Business Models in the Creative Economy.

Gillian Doyle is Professor of Media Economics and Director of the Centre for Cultural Policy Research (CCPR) at the University of Glasgow. 